\title{
A Preliminary Survey Of The Preferred Learning Methods For Interpretation Students
}

\author{
Michael Heinz, Hankuk University of Foreign Studies, Republic of Korea
}

\begin{abstract}
There are many different methods that individuals use to learn languages like reading books or writing essays. Not all methods are equally successful for second language learners but nor do all successful learners of a second language show identical preferences for learning methods. Additionally, at the highest level of language learning various areas of linguistic confidence may develop that distinguish learners of a second language as being, in terms of language proficiency, essentially equal but specifically different. This research sought to find out whether the specific learning tasks that individuals feel were most responsible for their linguistic growth show any correlation with their confidence in specific areas of language use. To answer this question, highly successful second language learners were asked to rank their confidence in various areas of language use and rate the significance of various learning methods that they utilized to achieve their current level of second language fluency. These highly successful second language learners were then surveyed from a South Korean interpretation and translation graduate school. As individuals who have already been vetted on the basis of their mastery of English, they provide a rare glimpse into the final product of both EFL and ESL programs.
\end{abstract}

Keywords: Confidence; Language Learning Tasks; Teaching Methods; ESL; EFL

\section{INTRODUCTION AND RESEARCH PROBLEM}

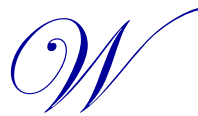

hile teaching academic skills to highly successful second language learners in an interpretation and translation graduate school in South Korea, the author has been continuously impressed with the linguistic mastery displayed by students in the program. They are far from perfect, but given certain factors in South Korea, their stories of linguistic success are quite remarkable. Two factors in particular make these students' stories worthy of study; the fact that despite tremendous learning efforts most South Koreans cannot comfortably speak English, and the extreme differences that exist between English and Korean.

Students in the author's graduate school program standout when compared to the generally accepted reality that learner outcomes for Koreans learning English tend to be very disappointing given the immense energy put into English learning. In South Korea in particular, there's no lack of English programs, one can find a private academy that teaches English in almost any and every neighborhood in Seoul. There are English programs for every conceivable age range and mothers fight hard to enroll their children in the best programs available. English is taught in the public schools system beginning in kindergarten and baby fairs are filled with English learning materials for toddlers and infants. With all the interest in English learning that takes place in South Korea, one would think that many or most South Koreans would be fluent in English, but this is sadly not the case. There are two simple explanations that may account for this; the differences that exist between Korean and English, or a possible systemic failure on the part of domestic Korean English programs.

The simplest explanation for why Koreans struggle to learn English may be the extreme differences that exist between English and Korean. Often people assume that languages are equally difficult but this most certainly is not the case. In particular, English and Korean may very well be two of the most dissimilar languages on the 
planet. The United States Department of State actually classifies Korean as a "superhard" language (2004). The Department of State has extensive language training requirements for overseas operatives in a variety of capacities so they have a financial need to classify the difficulty of languages to determine the time and resources needed to train personnel. Assuming that the language learner is a native English speaker, the State Department has three classifications for languages: "world languages", "hard languages", and "superhard languages." Within the "superhard languages" category, Korean alone is singled out as being "somewhat more difficult for native English speakers to learn to read and speak than others within the same category (2004)". So according to the United States Department of State, there are superhard languages, and Korean is the most difficult of those languages. Given the "superhard" nature of the difficulty that native English speakers face when learning Korean, it is reasonable to assume that Koreans experience at least some of the same challenges in learning English.

Given the generally low learner outcomes for Korean English learners and the very real difficulty that English poses for native Korean speakers, the author began to continuously wonder about the backgrounds of students in the interpretation and translation program and began to informally attempt to classify their success. However, this informal approach broke down very quickly. One student would credit their time spent overseas, another student might never have left Korea, another would credit a Korean university English program, and graduates from that same program might deride it, crediting some other source for the success. Thus it became clear that a formal study was not only needed but might yield really significant results for South Korean English learners.

In addition to the varied informal responses that students gave regarding their language learning process, the author could see subtle differences in the specific language capabilities of each student. While one student might possess greater broad command of English, there were notable differences in ability amongst differing academic topics. Interpreters and translators are often faced with the dilemma of needing to possess language skills for all areas, even when those areas differ as greatly as law and medicine. As such, certain students are likely to specialize after graduation in particular fields. This made the author wonder if differing learning backgrounds might consistently account for increased ability in specific areas.

\section{RESEARCH QUESTION}

Among the many methods that individuals use to successfully learn languages, are certain methods more likely to produce greater linguistic confidence in particular areas?

\section{LITERATURE REVIEW}

The research question required an examination of two different areas in the EFL/ESL discipline: classifying various learning methods and classifying different types of language proficiency. Both aspects of the discipline played an equal role in determining the kinds of questions asked of participants in the research survey.

In trying to determine what kinds of learning methods students used to achieve high level proficiency, a narrowing of the field was required because there is such a plethora of learning styles available today. In the end, interviews with students revealed that most of them had not had contact with more atypical learning styles like: the Audiolingual Method, Total Physical Response, the Silent Way, Neurolinguistic Programming, the Lexical Approach, etc. It may be the case that students did encounter some of these unique approaches to language learning but since none of the students interviewed cited these methods or showed any familiar with anything but the typical language learning methods currently and previously available, they were not included in the survey. Instead, interviews with students showed that they were more familiar with the Grammar Translation Method, the Communicative Approach, and immersion-based language learning. What follows is an overview of these methods, including praise and critique for each method of language learning.

Perhaps the most familiar form of language learning in both the East and the West is the Grammar Translation Method. It is sometimes referred to as the Classical Method because it comes from the methods used to in Western Europe to learn Latin and Greek. At its root the method was more of a form of self-study reliant on translating texts and it focused primarily upon establishing reading proficiency. However, over time this method was adapted to teach young pupils in the nineteenth century in Prussia, or modern day Germany. It was designed to facilitate rapid learning through a systematic and academic approach to languages (Chang 2011). 
The systemic approach that the Grammar Translation Method extolls can be varied in its implementation but it has some typical features. Primarily, the Grammar Translation Method involves the teaching of specific grammar structures and having students model the usage of these structures in controlled activities, orally or in written form. In addition, it is a teacher-centered approach with teachers giving information about the foreign language and students memorizing the information and being tested on their ability to replicate what they have learned in class. In this sense, students are passive receivers of knowledge. This method is associated with the following language tasks: learning lists of vocabulary and being tested on their equivalents in the students' native language; learning and being tested on the specific usage of grammatical structures, particularly exceptions and the ability to display high levels of grammatical accuracy; various memorization tasks; and various translation tasks. Altogether these language learning techniques represent the more traditional approach to learning languages and the Grammar Translation Method is still very popular in East Asia today.

The continued popularity of the Grammar Translation Method in East Asia can be attributed to several factors and indeed the Grammar Translation Method has many supporters. Since it is primarily a contrastive approach, it helps students understand the particular differences that exist between the first language (L1) and their second language (L2) and help students with language learning (Stern 1991). Chellapan takes a similar view and asserts that translation methods help students become aware of points of convergence and divergence between L1 and L2 and those translation methods refine students' analytic thinking and perceptive capacity for dealing with divergent thought (1982). Moreover, as a teaching method it favors the teacher in that the teacher can confidently control the class, be able to utilize a textbook, and not worry about traditional opposition to newer forms of language learning in places like East Asia (Ma Yinchu and Huang Jinyang 1992).

Though the Grammar Translation Method continues to popular in East Asia in particular, it is not without its critics. In a general sense, the most significant critique of the Grammar Translation Method is that it does not attempt to build communicative competence (Chang 2011). Brown H.D. asserts that the Grammar Translation method does not create students with any real communicative ability (1994). However, some respond to this critique by pointing out that in East Asia, communicative ability is not the goal of learning English (Lu 2004, Sano 1984). Students in East Asia are mostly concerned with passing standardized English tests and they have very few opportunities to use English in communicative capacity. While this is a valid critique, it also raises the question of why are students taking standardized English tests in the first place? If people are not trying to gain communicative capacity in a language, what exactly is the goal then of such comprehensive and enthusiastic efforts? Were the original intentions of Asian nations not to increase the communicative capacity of their people through the broad implementation of English courses? The Grammar Translation Method clearly has its uses but there is a valid concern that it has created a self-perpetuating language learning system that concerned with goals that may be antithetical to the very nature of language usage i.e. communication.

Developed to directly address concerns regarding the Grammar Translation Method, the Communicative Approach concerns itself chiefly with promoting the communicative capacity of the learner. What is now referred to as the Communicative Approach, began in the 1970s in England as an approach to language centered on a functional or communicative theory of language as espoused by British linguist Wilkins (1972). The approach found rapid acceptance in England and throughout the world and was rapidly included in language learning textbook design. The approach is intended to be student-centered and seeks to give the student more involvement in the learning process, making them an active learner or partner in the learning process. Its virtues as a learner-centered approach are extolled in the writings of Wilkins (1976), Widdowson (1978, 1999), Brumfit (2000), and Keith Johnson (1999).

The Communicative Approach is centered on the interactive expression of L2 with students providing authentic input. Language units focus on functions that need to be performed in the target language. Language lessons are delivered primarily in L2 and students are expected to interact with the teacher and each other in L2. Activities common to the approach include; playing games in L2, roleplaying specific situations using L2, learning to negotiate meaning and guess at ways to use the target language, finding ways to utilize new vocabulary in the form of self-expression, writing essays, reading texts in the target language and responding to them in the same language, etc. 
The activities that comprise the Communicative Approach have been criticized on a number of levels. One of the most significant critiques of the Communicative Approach was given in 1985 in Michael Swan's article, "A critical look at the Communicative Approach." Though Swan credits the Communicative Approach with the revitalization of language teaching methodology, he scathes what he sees as a dogmatically entrenched system of language teaching in which teachers do not question the most fundamental aspects of its operation (1985). In particular Swan takes aim at the notion of teaching students about "usage" and "use" which he feels may have philosophical meaning but no real impact on teaching languages because they are essentially the same (1985). Moreover Swan asserts that since all foreign language learners possess a first language, they do not need to be concerned with usage in a second language because it is a largely intuitive process that any individual can discern (1985). Thus he does not feel that students need to be taught strategies for guessing or interpreting meaning because they will do them automatically as language users (1985). Swan may be correct but given the extreme differences between English and most East Asian languages, it may be that notions of usage become less intuitive or universal as the root connections between languages become more disparate.

Swan is not the only critic of the Communicative Approach; in East Asia it has not received a warm welcome in some nations. In particular, it has been criticized as favoring native English speakers over domestic teachers of foreign language because it puts demands on domestic foreign language teachers that cannot be met, like total mastery of their foreign language (Harmer 2003). A study done in China found that class sizes, equipment, resources essentially limited teacher's ability to utilize the Communicative Approach (Burnaby \& Sun 1989). Moreover, Korean English teachers that participated in a study of the Communicative Approach expressed reservation about exploring meaning together with students because South Korean students expect teachers to be authorities and the act of negotiating meaning together in the classroom, or giving students the ability direct the classroom, makes the teacher appear weak (Li 1998). Also the Communicative Approach has been criticized on the grounds that it places greater emphasis on fluency, meaning students may develop poor levels of accuracy in the target language (Xu 1991, Li 2001).

In addition to the Grammar Translation Method and the Communicative Approach, the other dominant language learning method is immersion-based language learning. Immersion-based language learning can be done in the language learners L1 environment within specific facilities dedicated to the on-site total usage of L2, or by doing academic study in a foreign country in a student's foreign language. Core features of immersion education include: instruction almost entirely in L2, a curriculum that parallels that of an L1 curriculum, and exposure to L2 that is mostly limited to the classroom (Johnson \& Swain 1997). Immersion-based language learning has bilingualism as its goal and usually concerns itself with teaching bilingualism within a mono-lingual culture. In this sense, programs tend to concern themselves with additive bilingualism and subtractive bilingualism (Cummins 1998). Additive bilingualism means that the student retains mastery of L1 while mastering L 2 and subtractive bilingualism means that the students loses some mastery of L1 while attaining mastery of L2. The latter concern seems to occur mostly in situations where minority students in a community receive no support for their L1, and Cummins suggests that for most students immersion programs are unlikely to have any negative impact on students, while providing an overwhelming number of benefits (1998). A number of studies suggest that bilingual students have more elastic thinking and greater sensitivity to language than monolingual students (Cummins and Swain 1986, Diaz 1986). In a graduate school that concerns itself with interpretation and translation, the author does occasionally see the victims of subtractive bilingual education, particularly given the degree of bilingualism demanded of interpreters, but our program demands a level of bilingualism that is rare for individuals to achieve.

Overall, the types of language mastery that are derived from the Grammar Translation method, Communicative Approach and immersion-based curriculums are fairly broadly defined. The Grammar Translation method seems to improve accuracy while perhaps not greatly improving fluency. The Communicative Approach improves fluency while perhaps reducing accuracy. Also immersion-based language programs should achieve total mastery but may come at the price of losing some mastery in students' L1. While terms like fluency and accuracy have some meaning, they are rather vague notions of linguistic capacity. Immersion-based education's notion of subtractive bilingual impact is useful for students of interpretation and translation but a very challenging thing to demonstrate. When surveyed or simply asked students were not able to quickly grasp or quantify their abilities in terms of fluency, accuracy, or subtractive bilingual impact, though these concepts remain meaningful and worthy of future study. 
To look at language mastery broadly and in terms more relevant to interpretation and translation students, the author drew upon Cummins' notion of basic interpersonal communication skills (BICS hereafter) and cognitive academic language proficiency (CALP hereafter). This linguistic distinction is an important one that essentially separates students that "speak English well" from those who have the potential to be an interpreter. Fluency and accuracy are important measurements but measurements that are relative to usage. Being fluent and accurate when communicating interpersonally is considerably different from being fluent or accurate when expressing complex academic topics.

Cummins BICS/CALP distinction is a two language model that asserts that a students' learning of each language is not independently achieved. Instead there is an underlying dimension of conversational and academic communication that overlaps (2008). While the conversational aspects of a language may be very unique, the ability to describe things that are cognitively demanding tend to involve the use of the thinking skills that go beyond the surface differences of languages (Cummins 2008). In the absence of higher order thinking skills, a native speaker of a language that is a child might show perfect fluency with regard to talking on the playground, but be incapable of meaningful conversation about an advanced academic topic. Thus to possess a high of proficiency in a language, an underlying cognitive academic proficiency must be achieved. Generally the BICS/CALP distinction is very useful for language teachers in trying to determine a students' language proficiency and is at root a functional model for policy decisions in the classroom (Cummins 2008).

There have been a number of criticisms leveled at the BICS/CALP distinction. Edelsky asserts that the distinction is based on invalid testing, preferring a whole language approach for determining linguistic ability (1990). Cummins defends the BICS/CALP distinction by noting that Edelsky's view of determining linguistic ability to be too narrow to be functional (2000). Other critiques of the distinction stem from critiques of socio-cultural forces in education and the ways in which power structures impact the language of discourse in a community but these are distinctions that do little to impact the usefulness of the BICS/CALP distinction and often ignore the attention given to these distinctions by Cummins in his extensive work (Cummins 2000).

Criticism aside, the survey given utilized the BICS/CALP distinction because it works well in distinguishing types of language proficiency displayed by students. The author took the distinction a step further and looked at areas of linguistic competence within CALP to see if certain types of education had an impact on these areas. Due to the limitations of the survey, confidence was assessed instead of competence with the proviso that the author is well aware of the severe scrutiny that students underwent to become graduate students of interpretation and translation and thus participants in this survey. Given the stringent testing that the students were subjected to, which will be detailed below, the author felt assured that student confidence reflected competence in the various areas surveyed.

\section{SUBJECTS}

The participants in the survey were all students in the Korean-English department at the Graduate School for Interpretation and Translation (hereafter GSIT) at Hankuk University of Foreign Studies (hereafter HUFS). All of the students in the program possess a very high level of proficiency in both English and Korean, though all of them are native Korean speakers. To get into the program they had to pass through two rounds of testing. The first round of testing is a series of essays in both English and Korean based on listening to recorded passages or given prompts. The first round typically involves about 600 to as many as a 1000 applicants. The first round of testing produces about 150 candidates. Those 150 applicants are then given oral interviews lasting about 15 minutes. During the interviews the interviewees are asked some basic questions about themselves and then they are read a passage in English and asked to summarize the passage in Korean. After that the same process is repeated from Korean to English. The author has participated in all aspects of the testing and can attest to the severity of it all. The passages selected for interpretation are academic in nature and the students have no way of knowing their contents in advance. Also because the interpretation field involves working under pressure, the interviewers, are curt in dealing with interviewees, they are expected to answer question about themselves succinctly and are challenged directly when anything they say does not make sense. In other words, interviewees are not given the benefit of the doubt, as is the case in most interviews. Interviewees are expected to have excellent communication skills as those are skills needed to interpret. In the end, about 60 students make it through the process and become 
students at HUFS GSIT. There are several graduate schools that teach English-Korean translation, but HUFS GSIT is regarded as the top school in that field. As such the author feels confident that the students examined in this survey should be considered some of the most successful second language learners.

\section{DATA COLLECTION AND ANALYSIS}

To arrive at a sound examination of students' language learning backgrounds, 21 students participated in oral interviews to identify what students thought helped them the most. This process was very important in that it brought to light learning methods that had no originally occurred to the author. This interview process also made it clear the diverse backgrounds of the students merits a statistical approach to see which areas of overlap are most significant.

After the interviews were completed a questionnaire was created based on the interviews with students and the literature review. The items used in the survey asked students to rate individual language learning tasks, learning methods, and their confidence in various areas of language use. All of the items can be found in listed in Figure 1 on either the $\mathrm{x}$ axis or the $\mathrm{y}$ axis. The survey was then distributed to the students. Student participation was entirely voluntary and 64 out of 120 chose to participate. After the students had completed the survey, the results were run through SPSS version 20 to analyze the data.

\section{FINDINGS}

The data gleaned from the questionnaire showed that students attributed their current level of English proficiency to a variety of factors, but there were teaching styles and language tasks that students more often selected as being strongly responsible for their growth and English. In particular, the Communicative Approach, immersion-based language learning, reading, writing, and friendly interaction with native speakers received high scores. Even more revealing though were the Pearson's correlations which compared the teaching styles and language tasks that students thought were most responsible for their growth in English and their confidence levels when using English in a variety of settings. The correlations revealed strong positive correlations between high confidence in most areas of language use and immersion-based language learning, reading, writing, friendly interaction with native speakers, utilizing new vocabulary, teaching English, and playing games in English. Lastly, the extent to which students felt that speaking English was as comfortable as speaking Korean was correlated with teaching styles and language learning tasks and the results were very consistent with the above correlations. All of the figures discussed in the findings below can be found in Figure 1. The following paragraphs will examine teaching methods and confidence, and language tasks and confidence.

To begin, there was a clear preference by students for the Communicative Approach $(M=3.71)$ and immersion-based language learning $(M=3.71)$ when compared to the Grammar Translation Method $(M=2.78)$. Considering that the Grammar-Translation Method is the common method of language instruction in South Korea and East Asia, this finding was somewhat unexpected. In addition to a clear preference for the Communicative Approach and immersion-based language learning, correlative data found a fairly strong positive correlation between the immersion method and confidence, whereas the Grammar Translation Method showed generally negative correlations with various areas of language confidence. Immersion-based language learning had a positive relationship with every type of language confidence, and the highest correlation was with BICS $(r=.41)$, or casual use of English, and it was statistically significant. This means that not only did students think immersion-based language learning was responsible for their growth; immersion-based language learning creates successful language learners who are more confident in nearly every aspect of language use. 
Figure 1 Correlations and Means for Areas of Language Confidence, Language Learning Tasks, \& Language Teaching Styles (5-Point Likert Scale) N=64

\begin{tabular}{|c|c|c|c|c|c|c|c|c|c|}
\hline Language Learning Task & Mean & Std. Deviation & $\begin{array}{l}\text { BICS } \\
\text { Casual }\end{array}$ & $\begin{array}{c}\text { CALP } \\
\text { Academic }\end{array}$ & $\begin{array}{c}\text { Social } \\
\text { Sciences }\end{array}$ & Literature/Arts & Technology & $\begin{array}{c}\text { Scientific } \\
\text { Theory }\end{array}$ & $\begin{array}{l}\text { Bilingual } \\
\text { Comfort }\end{array}$ \\
\hline 1. Reading in English & 4.60 & .65 & .121 & $.255^{*}$ & .181 & .159 & .176 & $.252^{*}$ & .199 \\
\hline 2. Writing in English & 4.53 & .61 & $273^{*}$ & $.353^{* *}$ & $.359^{* *}$ & .212 & .206 & .197 & .179 \\
\hline $\begin{array}{l}\text { 3. Friendly Interaction } \\
\text { (w/Foreigners) }\end{array}$ & 4.31 & .66 & $.275^{*}$ & .224 & .099 & .149 & .115 & .184 & .163 \\
\hline 4. Utilizing New Vocabulary & 4.29 & .65 & .164 & .216 & $.363^{* *}$ & .133 & .151 & .193 & .034 \\
\hline 5. Watching Movies in English & 4.23 & .79 & $.270^{*}$ & .147 & -.075 & .192 & .015 & .221 & $.249^{*}$ \\
\hline 6. Positive Feedback & 4.20 & .73 & .114 & .141 & .166 & -.026 & .243 & .175 & -.076 \\
\hline 7. Mimicking English Speakers & 4.14 & .81 & .210 & .096 & .215 & .106 & .094 & .064 & -.039 \\
\hline 8. Reading Aloud in English & 4.10 & .77 & .028 & .084 & .007 & -.110 & .003 & .062 & .001 \\
\hline 9. Repetitious Viewings of Media & 4.04 & .89 & -.115 &.- .070 & -.050 & -.069 & -.111 & -.078 & $-.290^{*}$ \\
\hline 10. Listening \& Summarizing & 3.93 & .73 & $.249^{*}$ & .077 & .072 & .125 & -.017 & -.011 & -.134 \\
\hline 11. Memorizing Vocabulary & 3.89 & .83 & .135 & $.362^{* *}$ & $.363^{* *}$ & .184 & .141 & .075 & -.066 \\
\hline 12. Script Memorization & 3.59 & 1.00 & -.053 & -.084 & .086 & -.124 & -.087 & -.092 & -.227 \\
\hline 13.Teaching English & 3.56 & 1.19 & .169 & $.262^{*}$ & $.310^{*}$ & $.425^{* *}$ & $.269^{*}$ & $.349^{* *}$ & $.316^{*}$ \\
\hline 14. Talking to Yourself in English & 3.42 & 1.19 & .091 & .179 & $.285^{*}$ & .068 & .117 & $.247^{*}$ & .012 \\
\hline 15. Listening to Music in English & 3.32 & 1.08 & .078 & .067 & -.023 & .064 & -.076 & .121 & .166 \\
\hline 16. English Radio & 3.04 & 1.13 & -.057 & -.110 & -.021 & -.019 & .018 & .158 & -.134 \\
\hline 17. Familial Interaction & 3.04 & 1.35 & .023 & .075 & .074 & .075 & .004 & .081 & .130 \\
\hline 18. Playing Games in English & 2.98 & 1.18 & .148 & .167 & $.250^{*}$ & 208 & $.261^{*}$ & $.354^{* *}$ & $.341^{* *}$ \\
\hline 19. Studying for Standardized Tests & 2.85 & .97 & .160 & .130 & -.053 & .121 & .061 & .160 & .005 \\
\hline TEACHING METHODS & Mean & Std. Deviation & $\begin{array}{c}\text { BICS } \\
\text { Casual }\end{array}$ & $\begin{array}{c}\text { CALP } \\
\text { Academic }\end{array}$ & $\begin{array}{c}\text { Social } \\
\text { Sciences }\end{array}$ & Literature/Arts & Technology & $\begin{array}{c}\text { Scientific } \\
\text { Theory }\end{array}$ & $\begin{array}{r}\text { Bilingual } \\
\text { Comfort }\end{array}$ \\
\hline 1.Immersion & 3.71 & 1.13 & $.411^{* *}$ & .152 & .055 & $.257^{*}$ & .078 & .238 & $.273^{*}$ \\
\hline 2.Communicative Method & 3.71 & 1.01 & .232 & .088 & -.020 & .099 & -.032 & .061 & $.277^{*}$ \\
\hline 3.Grammar-Translation & 2.78 & 1.13 & -.021 & -.079 & .063 & -.161 & -.058 & -.024 & -.218 \\
\hline
\end{tabular}

** Correlation is significant at the 0.01 level (2-tailed). * Correlation is significant at the 0.05 level (2-tailed). 
While immersion-based language learning was largely validated by the study, the Communicative Approach received mixed to mild results and the Grammar Translation method was seen as less responsible for high growth and mostly negatively correlated to the different types of language confidence. Examining the Communicative approach, students indicated that it was significantly responsible for language growth but in terms language confidence correlations, the communicative approach was only strongly positively correlated with BICS $(\mathrm{r}=.23)$ and bilingual comfort $(\mathrm{r}=.27)$. The communicative approach was negatively correlated with social science $(\mathrm{r}=-.02)$ and technology language confidence $(\mathrm{r}=-.03)$, but this correlation was mild. On the other hand, the Grammar Translation Method was negatively correlated with BICS $(\mathrm{r}=-.02)$, CALP $(\mathrm{r}=-.07)$, literature/arts $(r=-.16)$, technology $(r=-.05)$, scientific theory $(r=-.02)$, and bilingual comfort $(r=-.21)$. Based on this data, the Grammar Translation Method does not appear to be the best teaching method for achieving high levels of language confidence.

In addition to selecting the teaching methods most responsible for their English growth, students also rated the significance of 19 language learning tasks. These language learning tasks were selected based on the pre-survey qualitative interviews done with students. Figure 1 shows the ranked means of each language learning task, and it clearly shows a preference for reading $(M=4.60)$, writing $(M=4.53)$, friendly interaction with Native speakers $(M=4.31)$, utilizing new vocabulary $(M=4.29)$, and watching movies in English $(M=4.23)$. The above items were not only selected more consistently as being responsible for English growth, they also so generally positive correlations with all types of language confidence. Specifically, writing English was strongly positively correlated with CALP $(r=.35)$ and Social Sciences $(r=.35)$. These correlations were significant as well. Also utilizing new vocabulary was positively correlated with Social Sciences (.36). This correlation was also significant.

Some of the language tasks students felt were responsible for their English growth actually showed negative correlations with most forms of language confidence. Repetitious viewings of media, script memorization, and English language teaching radio programs all showed consistent negative correlations with almost all types of language confidence. Most significantly, the largest negative correlations could be seen between repetitious viewing of media and BICS $(\mathrm{r}=-.11)$, and technology $(\mathrm{r}=-.11)$; script memorization and literature/arts $(\mathrm{r}=-.12)$; and English radio programs and CALP $(r=-.11)$. All were negatively correlated with bilingual comfort as well. Since these language tasks are all basic tasks used in the Grammar Translation Method (Korean English teaching radio programs typically use the Grammar Translation Method), this finding seems very consistent. However, memorizing vocabulary is considered a quintessential task in the Grammar Translation Method and unlike the other associated learning tasks, there was a strong positive correlation with CALP $(r=.36)$ and social Sciences $(r=.36)$, though it was also negatively correlated to bilingual comfort $(r=-.06)$ though only mildly so. This suggests that while not all aspects of the Grammar Translation Method are related to high levels of language confidence, some may be very useful methods of learning.

There were two language learning tasks, English teaching and playing games in English that were not the most commonly cited tasks responsible for language growth, but they actually showed strong and consistent correlations with high levels of language confidence. Teaching English showed strong positive correlations with every area of language confidence but most significantly with CALP $(\mathrm{r}=.26)$, social sciences $(\mathrm{r}=.31)$, literature/arts $(\mathrm{r}=.42)$, technology $(\mathrm{r}=.26)$, scientific theory $(\mathrm{r}=.34)$, and bilingual comfort $(\mathrm{r}=.31)$. Teaching is a form of presenting so it may not be so surprising that it shows such strong correlations. A future study might differentiate giving presentations from teaching English to see if there is any difference in students' responses. Playing games in English was considered by students to be the second least significant improver of English but it had strong positive correlations that were significant with social sciences $(r=.25)$, technology $(r=.26)$, scientific theory $(\mathrm{r}=.35)$, and bilingual comfort $(\mathrm{r}=.34)$. These findings indicate that both tasks are excellent ways to build confidence, though perhaps many students do not have much experience with them.

In East Asia is not uncommon for people to state that they study English only for tests and the findings indicated that the highly successful second language learners at HUFS GSIT did not have a high opinion of studying for standardized tests. It received the lowest score it terms of its significance as a language improver, but in terms of correlations it showed mild support for most types of language confidence. Studying for standardized English tests' strongest correlations were with BICS $(r=.16)$ and scientific theory $(r=.16)$, and it was singularly negatively correlated with social sciences $(r=-.05)$. All of these correlations were mild. This may reflect students' dislike of 
standardized tests. However, given that all of the correlations were not negative, as is the case with repetitious viewings of English media; this may suggest that standardized testing is not without value, presumably in terms of its effect on accuracy.

The final area that the findings will examine is which language tasks are strongly correlated with various types of language confidence. These findings could be useful in determining language tasks to build specific types of language confidence and perhaps competence as well. According to the findings, BICS is correlated with: friendly interaction with native speakers $(r=.27)$, writing in English $(r=.27)$, watching movies $(r=.27)$, listening and summarizing $(\mathrm{r}=.24)$, and mimicking English speakers $(\mathrm{r}=.21)$. CALP is correlated with: memorizing vocabulary $(\mathrm{r}=.36)$, writing in English $(\mathrm{r}=.35)$, teaching English $(\mathrm{r}=.26)$, reading in English $(\mathrm{r}=.25)$, friendly interaction with foreigners $(\mathrm{r}=.22)$, and utilizing new vocabulary $(\mathrm{r}=.21)$. Feeling confident when using English to talk about the social sciences is correlated with the following language tasks: utilizing new vocabulary $(r=.36)$, writing in English $(\mathrm{r}=.35)$, talking to yourself in English $(\mathrm{r}=.28)$, playing games in English $(\mathrm{r}=.25)$, and mimicking English speakers $(r=.21)$. Feeling confident when using English to talk about literature/arts is correlated with the following language tasks: teaching English $(\mathrm{r}=.42)$, writing in English $(\mathrm{r}=.21)$, and playing games in English $(r=.20)$. Feeling confident when using English to talk about technology is correlated with the following language tasks: teaching English $(\mathrm{r}=.26)$, playing games in English $(\mathrm{r}=.26)$, language tasks that involve positive feedback $(r=.24)$ and writing in English $(r=.20)$. Feeling confident when using English to talk about scientific theory is correlated with the following language tasks: playing games in English $(r=.35)$, teaching English $(\mathrm{r}=.34)$, reading in English $(\mathrm{r}=.25)$, and watching movies in English $(\mathrm{r}=.22)$.

\section{DISCUSSION AND LIMITATIONS}

As a preliminary study this data provides a lot of direction for additional research. The most significant limitation this study possesses is that it measures language confidence instead of language competence. While it is probably the case that confidence is strongly correlated with competence and the students surveyed in this program are highly successful second language speakers, assessing the full competence of students in each area would be better for making policy decisions based on data. The author is considering a range activities to assess the language competence of students in specific areas but the largest hurtle to overcome is funding. It would take a lot of testing from third parties to do an accurate assessment which requires considerable time and funding.

In terms of what this study says about language teaching, there are a few tentative conclusions that can be drawn. First, the Grammar Translation Method can produce top level English speakers. A large number of students credited it for their language growth, and the language learning tasks associated were credited as well. However, it seems that respondents that credit the Grammar Translation Method and its associated learning tasks do not feel as confident in every area of language usage as their counterparts. This is a troubling finding but not a particularly surprising one for anyone that has taught English in East Asia. The more significant find was that the Communicative Approach was not strongly correlated with language confidence, though it was more strongly correlated than the Grammar Translation Method. Seen by many as a panacea for the ills of the Grammar Translation Method, the Communicative Approach falls short of that based this data. Conversely, immersion-based education significantly outperformed the other two approaches and this suggests that it is the best approach to language learning.

Overall the unique student body surveyed in this preliminary study provided a lot of insight into the paths that individuals take to successfully learn another language.

\section{ACKNOWLEDGMENT}

This paper was supported by the 2012 Research Fund of Hankuk University of Foreign Studies, South Korea.

\section{AUTHOR INFORMATION}

Michael Heinz lectures fulltime at Hankuk University of Foreign Studies (Republic of Korea) in the Graduate School of Interpretation and Translation. There he teaches interpreters-in-training public speaking skills, stress management skills, critical thinking skills, and general academic skills to prepare them to work as both consecutive 
and simultaneous interpreters. Working with interpreters affords him the unique opportunity to research high level language learning tasks and profile the traits of successful language learners of two vastly differing languages like English and Korean. Michael Heinz earned both his B.S. in History and his Master of Arts in Education from Truman State University. E-mail: michaelhistory@gmail.com

\section{REFERENCES}

1. Brumfit, C. J. \& K. Johnson. (2000). The Communicative Approach to Language Teaching. Shanghai: Shanghai Foreign Language Education Press.

2. Burnby, B., \& Sun, Y. (1989). Chinese teachers' views of Western language teaching: Context informs paradigm. TESOL Quarterly, 23, 219-238.

3. Chang, Shi-Chuan. (2011) A Contrastive Study of Grammar Translation Method and Communicative Approach in Teaching English Grammar. English Language Teaching 4 (2), 13-24.

4. Chellapan, K.(1982). Translanguage, Translation and Second Language Acquisition. In F Eppert (Ed.), Papers on translation: Aspects, Concepts, Implications (pp. 57-63) Singapore: SEMEO Regional Language Center.

5. Cummins, J. (1979) Cognitive/academic language proficiency, linguistic interdependence, the optimum age question and some other matters. Working Papers on Bilingualism, No. 19, 121-129.

6. Cummins, J. (1998). "Immersion education for the millennium: What have we learned from 30 years of research on second language immersion?” In M. R. Childs \& R. M. Bostwick (Eds.) Learning through two languages: Research and practice. Second Katoh Gakuen International Symposium on Immersion and Bilingual Education. (pp. 34-47). Katoh Gakuen, Japan.

7. Cummins, J. (2000). "Putting Language Proficiency in Its Place: Responding to Critiques of the Conversational/Academic Language Distinction.” In J. Cenoz \& U. Jessner (Eds.) English in Europe: the acquisition of a third language (pp. 54-83). Clevedon: Multilingual Matters.

8. Cummins, J. (2008). "BICS and CALP: Empirical and Theoretical Status of the Distinction." Street, B. \& Hornberger, N. H. (Eds.). Encyclopedia of Language and Education, 2nd Edition, Volume 2: Literacy. (pp. 71-83). New York: Springer Science + Business Media LLC.

9. Cummins, J. \& Swain, M. (1986). Bilingualism in education: Aspects of theory, research and practice. London: Longman.

10. Diaz, R. M. (1986). Bilingual cognitive development: Addressing three gaps in current research. Child Development, 56, 1376-1388.

11. Edelsky, C. (1990). With literacy and justice for all: Rethinking the social in language and education. London: The Falmer Press.

12. Harmer Jeremy. (2003). How to teach English. Beijing: Foreign Language Teaching and Research Press.

13. Johnson, Keith. (1999). Encyclopedic dictionary of applied linguistics: A handbook for language teaching. Oxford: Wiley-Blackwell Press.

14. Johnson, R. K. \& Swain, M. (1997). Immersion education: International perspectives. Cambridge, UK: Cambridge University Press.

15. Li, D. (1998). “It's Always More Difficult Than You Plan and Imagine": Teachers' Perceived Difficulties in Introducing the Communicative Approach in South Korea. TESOL Quarterly 32, pp. 677-703.

16. Li, D. (2001). "Language Teaching in Translator Training". Babel 47-4, pp. 343-354.

17. Ma Yinchu \& Huang Jinyan. (1992). A Practical Guide to English Teaching Methodology. Changsha: Hunan Normal University Press.

18. Stern, H. H. (1992). Issues and options in language teaching (edited posthumously by Patrick Allen \& Birgit Harley). Oxford: Oxford University Press.

19. Swan, M. (1985a) A critical look at the Communicative Approach (1), ELT Journal 39/1, pp.2-12.

20. Swan, M. (1985b) A critical look at the Communicative Approach (2), ELT Journal 39/2, pp.76-87.

21. United States. Department of State. (2004). Language Continuum. School of Language Studies. Foreign Service Institute. Retrieved from http://fsitraining.state.gov/training/Language\%20Continuum.pdf

22. Widdowson, H. (1978). Teaching language as communication. Oxford: Oxford University Press.

23. Widdowson, H. (1999). Aspects of Language Teaching. Shanghai: Shanghai Foreign Language Education Press.

24. Wilkins, D. A. (1972). Linguistics in Language Teaching. Oxford: Arnold. 
25. Wilkins, D. A. (1976). Notional Syllabuses. London: Oxford University Press.

26. Xu Yingcai. (1991). A Comparison between the Audiolingual Approach and the Communicative Approach in Second-Language Teaching. In Li Yinhua. ed. Fudan workpapers on the Teaching of English to Nonmajors. Shanghai: Shanghai Foreign Language Education Press. 
NOTES 